\title{
Influence of Phase-Change Materials on Thermo-Physiological Comfort in Warm Environment
}

\author{
Damjana Celcar \\ Academy of Design in Ljubljana, Associated Member of University of Primorska, Vojkova 63, \\ 1000 Ljubljana, Slovenia \\ Correspondence should be addressed to Damjana Celcar; damjana.celcar@vsd.si
}

Received 28 December 2012; Revised 25 February 2013; Accepted 26 February 2013

Academic Editor: Phillip W. Gibson

Copyright (C) 2013 Damjana Celcar. This is an open access article distributed under the Creative Commons Attribution License, which permits unrestricted use, distribution, and reproduction in any medium, provided the original work is properly cited.

\begin{abstract}
The purpose of this research work is to investigate the influence of phase-change materials (PCMs) on thermo-physiological comfort of different male business clothing systems evaluated in warm environment. The impact of particular business clothing on the thermo-physiological comfort of the wearer during different physical activity and environmental conditions (between $25^{\circ} \mathrm{C}$ and $10^{\circ} \mathrm{C}$ with step of $5^{\circ} \mathrm{C}$ ), artificially created in a climate chamber, was determined experimentally, as a change of three physiological parameters of a human being: mean skin temperature, heart rate, and the amount of evaporated and condensed sweat. A questionnaire and an assessment scale were also used before, during, and after each experiment in order to evaluate the wearer's subjective feeling of comfort. The results of the performed research work show that male business clothing systems in combination with PCMs do not affect the thermal-physiological comfort of the wearer in warm environment significantly, except at an ambient temperature of $15^{\circ} \mathrm{C}$, where clothing systems in combination with PCMs produce a small heating effect. Furthermore, it was concluded that clothing systems in combination with PCMs indicate a small temporary thermal effect that is reflected in a slight rising or lowering of mean skin temperature during activity changes.
\end{abstract}

\section{Introduction}

Phase-change materials (PCMs), also called latent heat storage materials [1], are materials that can absorb, store, and release thermal energy as latent heat, while they go through a solid-liquid transition [2]. They were developed to regulate the human body temperature fluctuations, assuring the thermal-physiological comfort of the wearer. The most widespread PCMs in textiles are paraffin waxes (alkyl hydrocarbons such as eicosane, nonadecane, octadecane, etc.) with various phase change temperatures (melting and crystallization, i.e., freezing points) depending on their carbon numbers [3]. These liquid hydrocarbons are enclosed in microcapsules, a few microns in diameter. The microcapsule prevents leakage of the material during its liquid phase [2]. The microencapsulation of the PCMs involves enclosing them in thin and resilient polymer shells, so that the PCMs can be changed from solid to liquid and back again within the shells [3]. Microcapsules of phase-change materials can be incorporated into the spinning dope of manufactured fibres (e.g., acrylic, viscose), incorporated into the structure of foams and coated on the textile surface [2].

The developers and producers of PCMs in textile claim that garments made with PCMs will keep a person warm longer than conventional insulation when worn in cold environment. They also claim that its heat exchange produces a buffering effect in clothing, minimizing changes in skin temperature and prolonging the thermal comfort of the wearer [2]. However, most of the published research work of using PCMs on textiles was conducted on small pieces of fabric [4-10], but only a very few on garment $[2,11-13]$. Currently, PCMs are being used in a variety of outdoor apparel items (e.g., underwear, socks, gloves, jackets, sportswear, shoes, protective wear) [14]; therefore, we decided to incorporate those materials into male business clothing with the purpose to find out if these materials in combination with common textile materials for business clothing are able to interact with the human body and produce thermoregulatory control by affecting the microclimate between the clothing and the human skin under different climatic conditions. 


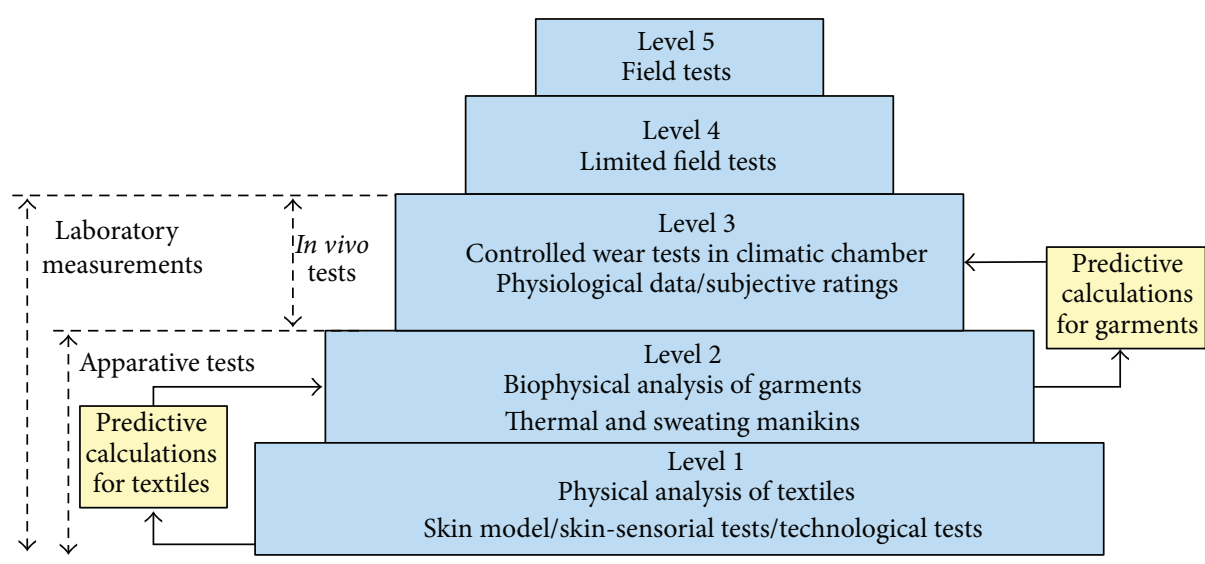

FIgURE 1: A five-level system for the analysis of the thermo-physiological comfort [15].

In view of the fact that people wear business clothing throughout the whole day, we decided to investigate the effect of PCMs incorporated in male business clothing systems on thermo-physiological comfort of the wearer under different physical activity that reminds as much as possible of real life situation of wearing clothes, such as sitting and walking on a treadmill, and different warm environmental conditions. The influence of different male business clothing systems made of common textile materials, as well as male business clothing systems that contain PCMs as lining or outerwear material, on the thermo-physiological comfort of the wearer was determined experimentally with the help of test persons, as a change of three physiological parameters: mean skin temperature, heart rate, and the amount of evaporated and condensed sweat. A questionnaire and an assessment scale were also used before, during, and after each experiment in order to evaluate the wearer's subjective feeling of comfort.

\section{The Evaluation of Thermo-Physiological Comfort}

Thermo-physiological comfort is directly related to physiological processes of human body and is the result of a balanced process of heat exchange between the human body, the clothing system, and the environment. It can be evaluated using several physical and physiological testing methods. A number of authors (Umbach, Mecheels, Parsons, and Goldman) have proposed the five-level system for developing and evaluating clothing comfort (Figure 1) [15].

Physical analysis of materials (Level 1) and biophysical analysis of clothing systems (Level 2) use some kind of device to simulate the skin's heat and/or water-vapour production. Tests can be carried out either on textile materials or on completed clothing systems [16]. Level 1 involves testing the thermal insulation and water-vapour resistance of the fabric layers with different measuring equipment, for example, Skin model [17], Sweating cylinder [16], Hot plate apparatus [18], KES-F7 Thermo Labo II system [19], and other methods. Level 2 involves an investigation of the thermal comfort properties of the whole clothing systems by using the thermal and sweating manikins. The use of thermal manikins in clothing research has a long history. Today, more than 100 thermal manikins are in use worldwide [20]. In previous research [21], we evaluated the thermal comfort properties of business clothing systems by using a sweating thermal manikin Coppelius that simulates heat and moisture production in a similar way to the human body. Levels 3, 4, and 5 involve human subjects and involve controlled climatic chamber tests, controlled field trials tests, and field evaluations, respectively. In the physiological tests the human subjects are dressed in the experimental clothing systems and perform some kind of given metabolic workload in a controlled or a real environment. Different physiological parameters (e.g., rectal and skin temperature, heart rate, weight loss, metabolic rate, etc.) and subjective perception of clothing comfort can all be determined according to interest of research. The principle of the user performance trial is to investigate clothing while in actual use, hence providing practical information. This will involve identifying a sample of users of the clothing and observing the properties over a period of time representing realistic conditions. Questionnaire techniques and possibly some physiological measures can be used [22].

\subsection{Measurement of Physiological Responses: Tests with Wear} Trials. As the wear comfort is directly related to physiological processes, it is possible to measure it quantitatively. An important way to measure the thermo-physiological comfort is to perform wearer trials with human subjects. These could be performed either under controlled climatic and activity scenarios in a climatic chamber or under practical conditions in real wearing [23].

The physiological reactions of wear trials can objectively be measured as a change of physiological parameters or perceived subjectively, based on the assessment of thermal comfort using subjective judgement scales. The temperature and humidity in the microclimate at different points, the rectal temperature, and the skin temperature at different positions, the heart rate, the oxygen consumption, the weight loss, and other physical and physiological values of interest regarding the subject and in the environment can all be determined with wear trials. Physiological tests have also 


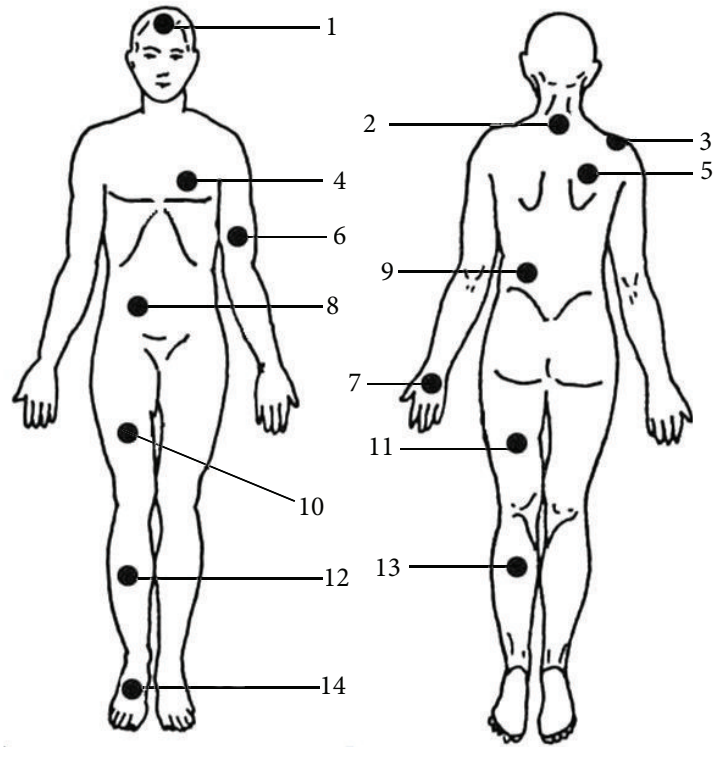

(1) Forehead

(8) Right abdomen

(2) Neck

(9) Left paravertebral

(3) Right shoulder

(10) Right anterior thigh

(4) Left upper chest

(11) Left posterior thigh

(5) Right scapula-back

(12) Right shin

(6) Left arm

(13) Left calf

(7) Left hand

(14) Right instep

FIGURE 2: Measuring points on the skin for the determination of mean skin temperature [24].

been used to establish the effect of body motion on the heat exchange properties of clothing systems [16]. In this research, we measured three physiological parameters of a human being: mean skin temperature, heart rate, and the amount of evaporated and condensed sweat, which are shortly presented in continuation.

Skin temperature can be measured by placing sensors on the skin (thermocouples, thermistors, etc.) or by measuring thermal radiation which has the advantage of noncontact. Mean skin temperature is the mean value of the skin over the whole body and can be measured with an infrared scanning radiometer [22]. According to the ISO 9886, 2004 [24], for the determination of the mean skin temperature from local temperatures measured at different body locations, many weighting schemes have been proposed, using a number of measuring points ranging from 1 to 14 . In order for the measurements to be made in a systematic way and the results to be more comparable, three weighting schemes, with 4,8 , or 14 measuring points, are proposed. The location of the 14 local temperature sites shows Figure 2.

The mean skin temperature $T_{\text {pon }}$ is calculated by weighting each of the local temperatures with a coefficient corresponding to the relative surface of the body area that each measuring point represents. Mean skin temperature can be calculated according to following expression [24]:

$$
\begin{aligned}
T_{\text {pon }}= & 0.07 \cdot T_{\text {fore head }}+0.175 \cdot T_{\text {back }}+0.175 \cdot T_{\text {chest }} \\
& +0.07 \cdot T_{\text {arm }}+0.07 \cdot T_{\text {shoulder }}+0.05 \cdot T_{\text {hand }} \\
& +0.19 \cdot T_{\text {thigh }}+0.2 \cdot T_{\text {shin }}\left({ }^{\circ} \mathrm{C}\right) .
\end{aligned}
$$

Heart rate in beats per minute provides a general index to stress on the body which can be caused by activity, static exertion, thermal strain, psychological responses, and so on. To determine the thermal effects on heart rate, one can divide overall heart rate into a number of (nonindependent) components. Heart rate can be measured using a simple pulse detected with the hand placed on the wrist or neck; infrared techniques, electrical sensors, and temperature sensors relating to changing blood flow in the finger or earlobe, portable pulse reading devices, and so one can also be used [22]. In our research, heart rate was measured on the principle of the EKG signal, using three electrodes connected with portable Par-Port measuring system.

Amount of evaporated and condensed sweat (body mass loss) is related to thermal strain, mainly due to sweat loss. It is also affected by evaporative loss due to breathing and differences in mass between expired $\mathrm{CO}_{2}$ and inspired $\mathrm{O}_{2}$. A simple method of measurement is to weight a subject nude before exposure, clothed before exposure, clothed after exposure, and nude after exposure. The following condensed sweat (sweat trapped in clothing) can be determined from weighting of clothing after and before exposure [22].

2.2. Measurement of Psychological Responses: Subjective Measures. The methods for evaluating subjective assessment of thermal comfort use different scales to measure thermal sensation and comfort. There are a number of subjective scales which have been used in the assessment of thermal environments; the most common of these are the sevenpoint scales of ASHRAE (1966). International standard ISO 10551: 1995 [25] presents the principles and methodology for the construction and use of scales for assessing the thermal environment. Scales are divided into two types: personal and environmental. Those related to the personal thermal state may be perceptual, how do you feel now? (e.g., hot), affective, How do you find it? (e.g., comfortable), and preference, How would you prefer to be? (e.g., warmer). Those related to the environment fall into two types: acceptance-Is the environment acceptable?, and tolerance: is the environment tolerable? [22, 25].

\section{Materials and Methods}

3.1. Experimental Clothing Systems and Textile Materials. Five male business clothing ensembles (cs1-cs5) of 3-layer clothing system (short underwear, long sleeve male shirt, and male suit with lining) were used for this investigation (Table 1).

The same underwear and male shirt were used for testing. The thermal comfort properties of male business clothing systems were measured by using a sweating thermal manikin 
TABLE 1: Clothing ensembles of business clothing systems with fabric content of textile materials.

\begin{tabular}{|c|c|c|c|c|c|c|c|}
\hline \multirow{2}{*}{$\begin{array}{l}\text { Clothing system } \\
\text { layer }\end{array}$} & \multirow{2}{*}{ Fabric sample } & \multirow{2}{*}{ Fabric content of textile materials } & \multicolumn{5}{|c|}{ Combination of clothing system } \\
\hline & & & $\operatorname{cs} 1$ & $\operatorname{cs} 2$ & $\operatorname{cs} 3$ & $\operatorname{cs} 4$ & $\operatorname{cs} 5$ \\
\hline Underwear & TK15 & $100 \% \mathrm{CO}$ & $*$ & $*$ & $*$ & $*$ & $*$ \\
\hline Shirt & TK07 & $78 \% \mathrm{CO}, 22 \% \mathrm{PES}$ & * & * & * & * & * \\
\hline \multirow{2}{*}{ Lining for jacket } & TK12 & $100 \% \mathrm{CV}$ & * & * & * & * & \\
\hline & TK21 & 1.layer: $100 \%$ CV, 2.layer: Outlast ${ }^{\circledR}$ : Acryl with PCMs & & & & & * \\
\hline \multirow{4}{*}{ Male suit } & TK01 & $100 \%$ WO & * & & & & $*$ \\
\hline & TK02 & $88 \%$ WO, $12 \%$ PA & & * & & & \\
\hline & TK03 & $98 \% \mathrm{WO}, 2 \% \mathrm{EL}$ & & & $*$ & & \\
\hline & TK22 & $68 \%$ Outlast $^{\circledR}$ : Acryl with PCMs, $28 \%$ WO, $4 \%$ EL & & & & $*$ & \\
\hline
\end{tabular}

TABLE 2: Description of test materials and their basic properties [26].

\begin{tabular}{|c|c|c|c|c|c|c|c|}
\hline $\begin{array}{l}\text { Fabric } \\
\text { sample }\end{array}$ & $\begin{array}{l}\text { Clothing } \\
\text { system layer }\end{array}$ & Fabric content & $\begin{array}{l}\text { Weight } \\
\mathrm{W} / \mathrm{gm}^{-2}\end{array}$ & $\begin{array}{c}\text { Thickness } \\
\mathrm{h}^{\mathrm{a}} / \mathrm{mm} \\
\end{array}$ & $\begin{array}{c}\text { Air } \\
\text { permeability } \\
Q_{\text {air }} / \operatorname{lm}^{-2} s^{-1} \\
\end{array}$ & $\begin{array}{c}\text { Thermal } \\
\text { resistance } \\
R_{\mathrm{ct}} / \mathrm{m}^{2} \mathrm{KW}^{-1}\end{array}$ & $\begin{array}{c}\text { Water-vapour } \\
\text { resistance } \\
R_{\mathrm{et}} / \mathrm{m}^{2} \mathrm{PaW}^{-1} \\
\end{array}$ \\
\hline TK01 & Male suit & $100 \% \mathrm{WO}$ & 179.0 & 0.51 & 323.5 & 0.016 & 0.994 \\
\hline TK02 & Male suit & $88 \% \mathrm{WO}, 12 \% \mathrm{PA}$ & 206.0 & 0.49 & 75.2 & 0.011 & 1.118 \\
\hline TK03 & Male suit & $98 \% \mathrm{WO}, 2 \% \mathrm{EL}$ & 189.0 & 0.49 & 223.0 & 0.011 & 0.795 \\
\hline TK07 & Shirt & $78 \%$ CO, $22 \%$ PES & 85.0 & 0.21 & 322.0 & 0.005 & 0.451 \\
\hline TK12 & Liner for suit & $100 \% \mathrm{CV}$ & 76.0 & 0.11 & 596.0 & 0.001 & 0.198 \\
\hline TK15 & Underwear & $100 \% \mathrm{CO}$ & 221.0 & 1.59 & 618.0 & 0.036 & 2.340 \\
\hline TK21 & Liner for suit & $\begin{array}{l}\text { 1.layer: } 100 \% \mathrm{CV} \text {, } \\
\text { 2.layer: Outlast }{ }^{\circledR} \text { : } \\
\text { acryl with PCMs }\end{array}$ & 93.0 & 0.21 & 151.0 & 0.002 & 0.474 \\
\hline TK22 & Male suit & $\begin{array}{c}68 \% \text { Outlast }^{\circledR}: \text { acryl } \\
\text { with PCMs, } \\
28 \% \text { WO, } 4 \% \text { EL }\end{array}$ & 168.0 & 0.49 & 277.0 & 0.014 & 0.842 \\
\hline
\end{tabular}

${ }^{\mathrm{a}}$ Thickness under a pressure by $0.069 \mathrm{gfcm}^{-2}(1 \mathrm{gf}=0.9807 \mathrm{cN} \approx 1 \mathrm{cN})$.

Coppelius under different environmental and sweating conditions and are published in Celcar et al's work [21]. In this research we varied textile materials of male suits and linings for the male suit. Table 2 shows a review of the selected materials and their basic properties, which are published and discussed in Celcar et al. [26]. The determinations of basic material, thermal, and water-vapour transmission properties in steady-state conditions were carried out according to standardized test methods and are published in Celcar et al.s work [26]. Among the selected textiles two of them containing Outlast ${ }^{\circledR}$ PCMs with melt peak between $27-30^{\circ} \mathrm{C}$, declared from textile supplier. Textile TK21 is coated textile material with PCMs Outlast ${ }^{\circledR}$ particles on the left side and is useful for lining outerwear, while textile TK22 has builtin Outlast ${ }^{\circledR}$ PCMs in acrylic fibers and is useful for lighter outerwear.

3.2. Subjects. Five male persons between 21 and 23 years of age $(22.2 \pm 0.8)$ participated in the wear trial test. They were on average $180.2 \mathrm{~cm}$ tall $(180.2 \pm 4.6)$ and of the average weight of $80.0 \mathrm{~kg}(80.0 \pm 2.4)$. The general purpose, procedure, and risks were fully explained, and informed consent was given by all subjects, but they were not informed about the details of the clothing materials to avoid any influence on their subjective ratings.

3.3. Experimental Protocol. All tests with wear trials were performed under artificially created environmental conditions in a climate chamber at a constant air movement of $0.2 \mathrm{~ms}^{-1}$ and at four different environmental temperatures from $25^{\circ} \mathrm{C}$ till $10^{\circ} \mathrm{C}$ with step of $5^{\circ} \mathrm{C}$ and $50 \%$ relative humidity. The experimental protocol was approved by the Slovenian Ethic Committee, (Komisija Republike Slovenije za medicinsko etiko 12.02.2008). Participants (test persons) followed an exercise protocol for 110 minutes, consisting of five period activities (Figure 3) as follows:

(1) Activity (A1): a 20-minute rest on a chair (preconditioning) at $20-23^{\circ} \mathrm{C}$ and around $50 \% \mathrm{RH}$.

(2) Activity (A2): 20 minutes of sitting on a chair in a climate chamber at an ambient temperature from $25^{\circ} \mathrm{C}$ till $10^{\circ} \mathrm{C}$ (with step of $5^{\circ} \mathrm{C}$ ) and $50 \% \mathrm{RH}$.

(3) Activity (A3): 30 minutes of walking $3.5 \mathrm{kmh}^{-1}$ on a treadmill in a climate chamber at an ambient temperature from $25^{\circ} \mathrm{C}$ till $10^{\circ} \mathrm{C}$ (with step of $5^{\circ} \mathrm{C}$ ) and $50 \% \mathrm{RH}$. 

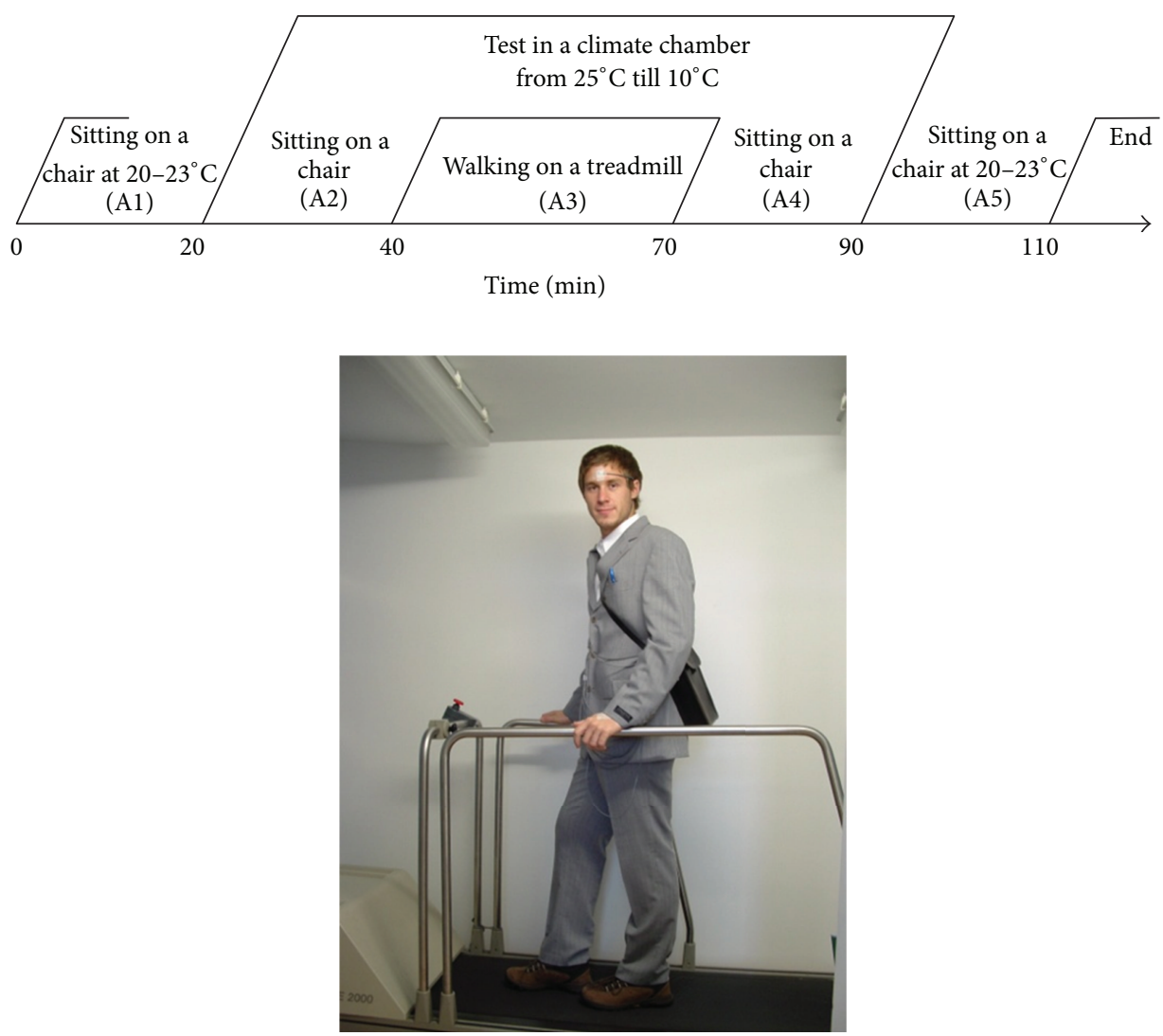

Figure 3: Test protocol of the wear trial tests.

(4) Activity (A4): 20 minutes of sitting on a chair in a climate chamber at an ambient temperature from $25^{\circ} \mathrm{C}$ till $10^{\circ} \mathrm{C}$ (with step of $5^{\circ} \mathrm{C}$ ) and $50 \% \mathrm{RH}$.

(5) Activity (A5): a 20 -minute rest on a chair at $20-23^{\circ} \mathrm{C}$ and around $50 \% \mathrm{RH}$.

3.4. Measurements. Skin temperature and heart rate were measured with computer controlled portable measuring equipment Par-Port system continuously in the interval of one minute. Skin temperature was measured at eight measuring points with thermoelements, according to the standard method, as defined by ISO 9886: 2004 [24], while heart rate was measured on the principle of the EKG signal, using three electrodes. Human subjects, all garments, and shoes were precisely weighed before and after each test protocol to estimate the sweat loss from the body and to determine the amount of sweat accumulated in the tested garments. Subjective assessment of thermal comfort was obtained during the experiment according to a questionnaire and an assessment scale defined by ISO 10551: 1995 [25]. Subjects answered at predetermined time of experiment using specially designed questionnaires: last minute of each period and second minute of next period.

3.5. Statistical Analysis. The experimental data were analyzed using an analysis of variance (ANOVA) to detect significant differences in mean skin temperatures during wearing particular business garments. When ANOVA revealed a significant effect, the Student's $t$-tests with Bonferroni adjustment were used to identify significant differences between the skin temperatures of two independent groups (clothing systems).

\section{Results and Discussion}

The results of research of the influence of male business clothing systems, made of conventional textile materials, as well as materials that contain PCMs, on thermo-physiological comfort at different warm environmental conditions and physical activity that reminds as much as possible of real life situation of wearing clothes, are presented as the results of mean skin temperature and heart rate measurements, as well as subjective evaluations of thermal comfort. Figure 4 shows the results of mean skin temperature changes of test persons, which wear different clothing systems in climate chamber at an ambient temperature of $25^{\circ} \mathrm{C}$ and on Figure 5 at an ambient temperature of $20^{\circ} \mathrm{C}$.

It can be seen from Figure 4 that mean skin temperature $\left(T_{\text {pon }}\right)$ values, obtained at an ambient temperature of $25^{\circ} \mathrm{C}$, are the highest at wearing clothing system cs3, while at wearing clothing system cs2 are the lowest. By comparing clothing system cs1 (male suit with viscose lining) and clothing system cs5 (male suit with viscose lining and PCMs), which differentiate only in textile materials of male suit lining, it can 

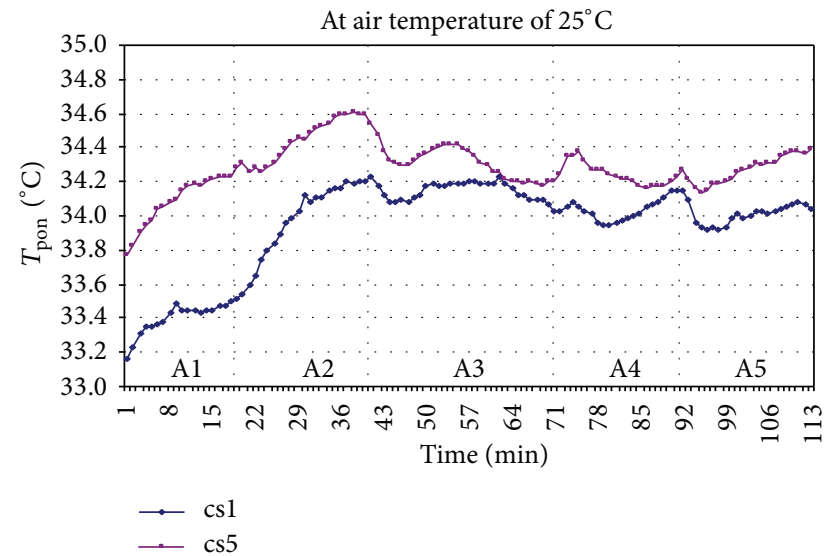

(a) Clothing systems cs1 and cs5

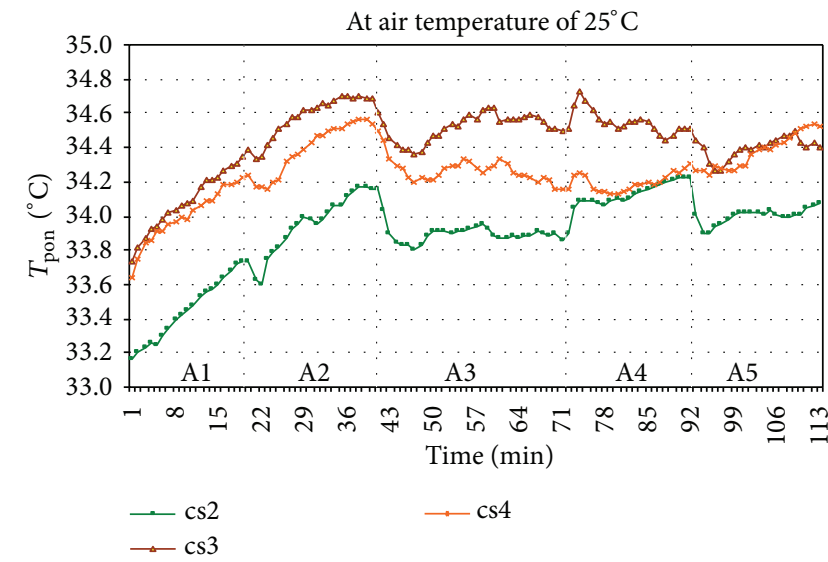

(b) Clothing systems cs2, cs3 and cs4

FIGURE 4: The change of mean skin temperature depending on of exposed time of research at an ambient temperature of $25^{\circ} \mathrm{C}$.

be noted (Figure 4(a)) that mean skin temperature measured in second activity (A2), when sitting in a climate chamber and wearing clothing system csl, is rising for $0.7^{\circ} \mathrm{C}$, while at wearing clothing system cs5, it is rising for about $0.4^{\circ} \mathrm{C}$.

When test persons walked on a treadmill during third activity (A3) mean skin temperature at wearing clothing systems cs1, cs2, and cs3 in average decreases for $0.1^{\circ} \mathrm{C}$, at wearing clothing system $\operatorname{cs} 5$ for $0.4^{\circ} \mathrm{C}$ and at cs 4 (clothing system with PCMs) for $0.3^{\circ} \mathrm{C}$. This means that microcapsules PCMs in clothing system cs 5 and cs 4 absorb excess heat, so that achieved a slight cooling effect. It can be seen from the results, gathered at an ambient temperature of $25^{\circ} \mathrm{C}$, that mean skin temperature in average ranges a little up to $34.0^{\circ} \mathrm{C}$, while during walking, a little below. In spite of little lower $T_{\text {pon }}$ measured during walking, test persons felt thermally uncomforted, because it was warm. By analysing the results of subjective evaluation of thermal comfort, we noted that the experimental business clothing at the ambient temperature of $25^{\circ} \mathrm{C}$ causes slight thermal discomfort, first of all while walking and after walking [27].

At an ambient temperature of $20^{\circ} \mathrm{C}$, Figure 5, obtained mean skin temperature values range between $33.0^{\circ} \mathrm{C}$ and $34.0^{\circ} \mathrm{C}$, thus in range when people felt optimal thermal comfort, what we noted also from subjective evaluation of thermal comfort [27]. Test persons felt thermally comfortable while sitting in second (A2) and fourth (A4) activities, while walking on a treadmill during third activity (A3) they felt a little uncomfortable, except at wearing clothing system cs4 (male suit with PCMs) where test persons felt comfortable [27]. By comparing clothing systems csl and cs5, it can be seen (Figure 5(a)) that mean skin temperature at wearing clothing system cs5 is lower in third (while walking, A3), fourth (A4), and last (A5) activities, while walking on a treadmill (A3) and also after walking in fourth activity (A4), it was noted that, at wearing clothing system csl, mean skin temperature rises; while at wearing clothing system cs5, mean skin temperature was more constant. This means that microcapsules PCMs in clothing system cs 5 absorb excess heat so that a slight cooling effect is achieved. We noted also by comparing clothing system similar findings cs 2 and cs 3 with clothing systems cs 4 (Figure 5(b)). At wearing clothing system cs4, it was noted that during walking (A3) and after walking (A4) measured mean skin temperature is the lowest, and in spite of this, test persons felt thermally comfortable. This means that, also at wearing clothing system cs4, microcapsules PCMs absorb excess heat and with this effect enable people to feel comfortable. The results also show that at clothing systems cs 4 and cs5 mean skin temperatures in the third period and also in the fourth period are little lower, on average by $0.4^{\circ} \mathrm{C}$, because the micro-PCMs absorb heat while walking and produce a cooling effect.

Further, the results of mean skin temperature changes of test persons, obtained at an ambient temperature of $15^{\circ} \mathrm{C}$, are presented in Figure 6 and at an ambient temperature $10^{\circ} \mathrm{C}$ on Figure 7.

At the ambient temperature of $15^{\circ} \mathrm{C}$, mean skin temperatures range between $31.5^{\circ} \mathrm{C}$ and $32.0^{\circ} \mathrm{C}$ while walking, and between $32.0^{\circ} \mathrm{C}$, and $33.0^{\circ} \mathrm{C}$ while sitting in the climate chamber. The highest values of mean skin temperatures obtained in first (A1), second (A2), and third (A3) activities are noted at wearing clothing system cs3, while the lowest, at wearing clothing system cs2. By comparing clothing systems cs1 and cs5 (Figure 6(a)) it can be noted that, after walking on a treadmill, while sitting (A4), mean skin temperature in the clothing system $\operatorname{cs} 5$ rises for $0.7^{\circ} \mathrm{C}$ at the end of the fourth activity, while at wearing, clothing system csl rises only for $0.3^{\circ} \mathrm{C}$. This means that PCMs microcapsules incorporated in clothing system cs5 release absorbed heat while test persons sit and thus cause a small heating effect, which is reflected in increase of mean skin temperature. It is evident from results gained while sitting of test persons (A2) that mean skin temperatures measured in all clothing systems at entering climate chamber decrease, the least in clothing system cs4. During walking of test persons on a treadmill, it is evident even additional decrease of mean skin temperature, which ranges around $32.0^{\circ} \mathrm{C}$. Beside this test persons while walking felt comfortable [27]. By comparing clothing systems cs2 and cs4, it is noted that in clothing system cs4 gained mean skin 


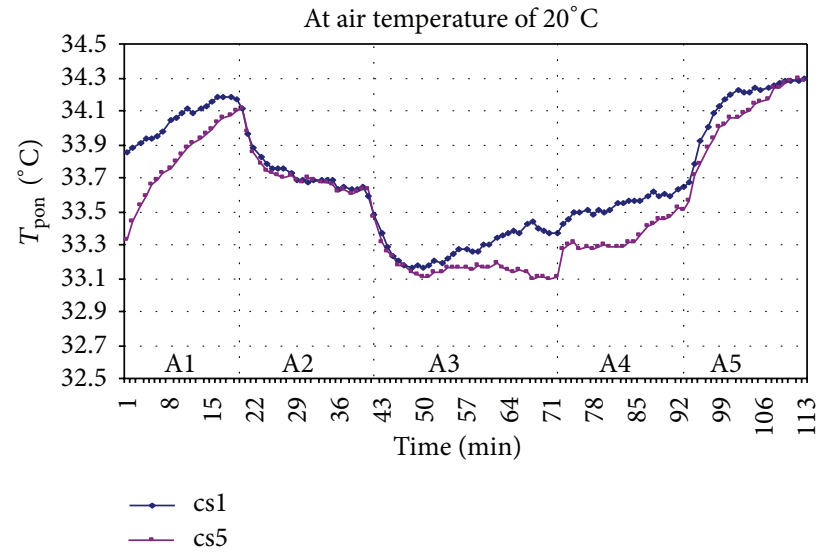

(a) Clothing system csl and cs5

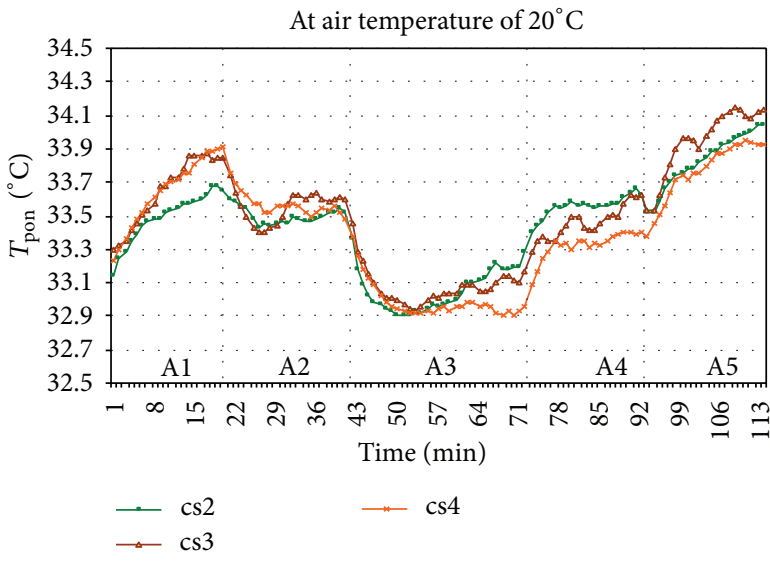

(b) Clothing system cs2, cs3 and cs4

FIGURE 5: The change of mean skin temperature depending on of exposed time of research at an ambient temperature of $20^{\circ} \mathrm{C}$.

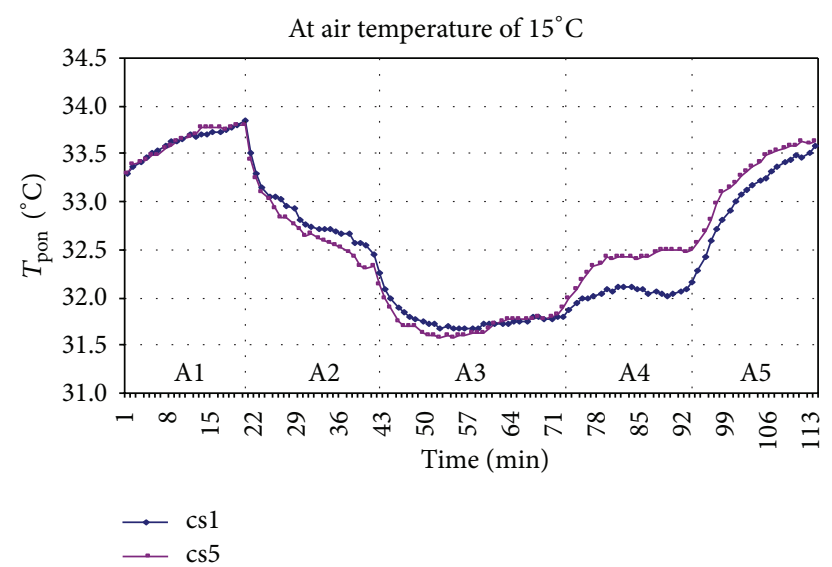

(a) Clothing systems cs1 and cs5

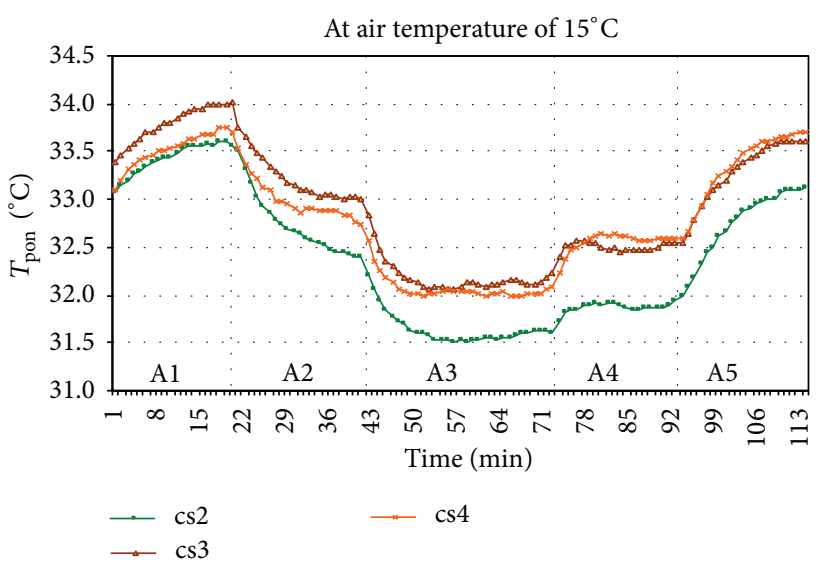

(b) Clothing systems cs2, cs3 and cs4

Figure 6: The change of mean skin temperature depending of exposed time of research at an ambient temperature of $15^{\circ} \mathrm{C}$.

temperature is a little higher, first of all after walking, while sitting (A4), where measured $T_{\text {pon }}$ is the highest. This means that also at wearing clothing system cs4 an effect of PCMs is evident, which is expressive after walking in the fourth activity, when PCMs release absorbed heat and thus cause a small heating effect, which is reflected in the increase of mean skin temperature. It can also be seen that, in the fourth activity of testing, mean skin temperatures measured in the clothing systems cs 4 and cs5 are little higher, on average by $0.6^{\circ} \mathrm{C}$, because the micro PCMs release absorbed heat (while walking) and thus cause a heating effect.

At an ambient temperature of $10^{\circ} \mathrm{C}$, when test persons wear clothing systems without a coat (clothing systems cslcs5, Figure 7), mean skin temperatures measured when sitting in a climate chamber (A2) range between $31.2^{\circ} \mathrm{C}$ and $32.5^{\circ} \mathrm{C}$ and during walking around $30.5^{\circ} \mathrm{C}$, thus under the comfort limits. The highest mean skin temperature is measured at wearing clothing system cs3, which offers the highest thermal insulation [21], while the lowest mean skin temperature is measured at wearing cs4, which offers the lowest thermal insulation [21]. The biggest decrease of mean skin temperatures is noted while walking (A3) when they range between $29.9^{\circ} \mathrm{C}$ and $31.8^{\circ} \mathrm{C}$ and in fourth activity after walking (A4) when they range in average of $30.1^{\circ} \mathrm{C}$ and $31.4^{\circ} \mathrm{C}$. This means that on average mean skin temperatures range under the comfort limits $\left(32.0^{\circ} \mathrm{C}\right)$ and that experimental male business clothing systems without a coat are not suitable for wearing at an ambient temperature of $10^{\circ} \mathrm{C}$. Also from subjective evaluations, it is evident that test persons at wearing clothing systems without a coat at an ambient temperature of $10^{\circ} \mathrm{C}$ felt uncomfortable, because they were cold [27].

Statistical analysis of variance showed that gained differences between mean skin temperatures measured in male business clothing systems with and without PCMs particles in warm environment are not significant, except at an ambient temperature $15^{\circ} \mathrm{C}$, where PCMs in clothing systems cs4 (male suit with PCMs) and cs5 (male suit with viscose/PCMs lining) release absorbed heat and thus cause a small heating effect, which is reflected in increase of mean skin temperature [28]. 


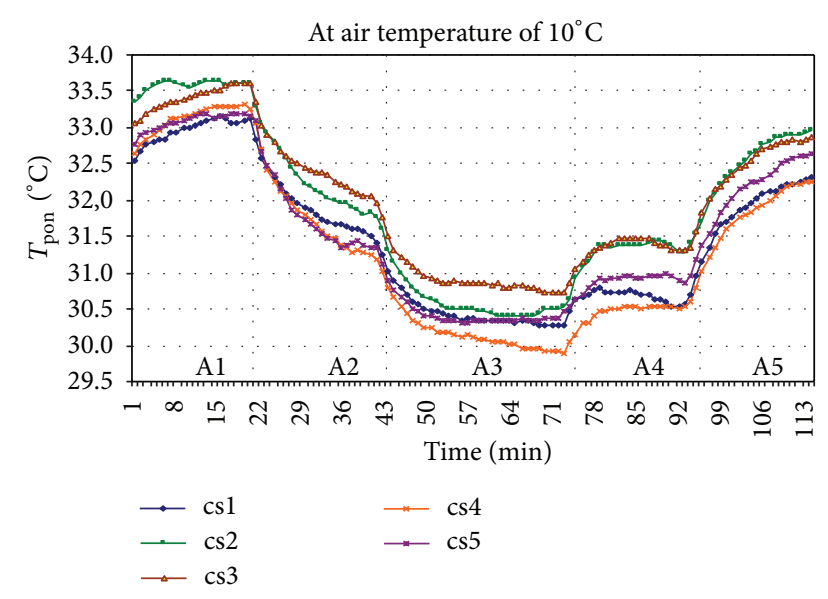

Figure 7: The change of mean skin temperature dependence of exposed time of research at an ambient temperature of $10^{\circ} \mathrm{C}$.

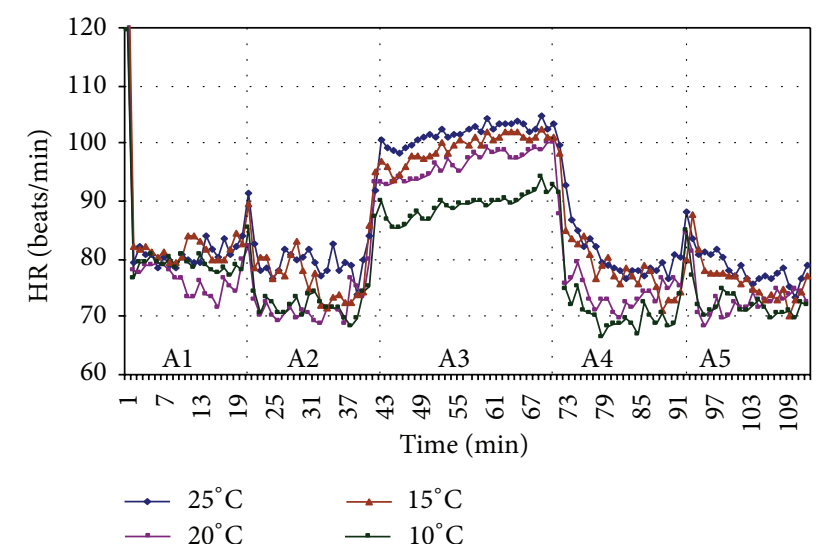

FIGURE 8: Time dependent mean heart rate of person under different ambient temperatures.

Figure 8 shows that mean heart rate values increase with the activity of test persons while walking and also increase with the ambient temperature. The lowest heart rate is evident when sitting in a climate chamber (fourth period, A4) at the ambient temperature of $10^{\circ} \mathrm{C}$, and the highest while walking on a treadmill (A3) at the ambient temperature of $25^{\circ} \mathrm{C}$.

The analysis of the mean evaporated sweat, calculated from the weight of testing persons before and after the experiment, shows that most of the sweat evaporated at the ambient temperature of $25^{\circ} \mathrm{C}$ and the least at the ambient temperature $10^{\circ} \mathrm{C}$, which means that the evaporated sweat as physiological parameter is directly dependent from the exposure to different environmental conditions [28]. By analysing the results of subjective evaluation of thermal comfort [27], it can be seen that the experimental business clothing at the ambient temperature of $25^{\circ} \mathrm{C}$ causes slight thermal discomfort, first of all while walking and after walking. The feeling of thermal comfort is achieved at the ambient temperatures of $20^{\circ} \mathrm{C}$ and $15^{\circ} \mathrm{C}$. Thermal discomfort is felt at the ambient temperature of $10^{\circ} \mathrm{C}$ when wearing business clothing systems without a coat [27].

\section{Conclusions}

The analysis of the thermo-physiological comfort of male business clothing systems, evaluated through wear trials, shows that environmental conditions and activity levels have a considerable impact on the physiological parameters of the subjects and subjective assessment of thermal comfort in warm environment. It was noted that the highest values of mean skin temperatures were evident at an ambient temperature $25^{\circ} \mathrm{C}$, where in average range between $34.0^{\circ} \mathrm{C}$ and $34.5^{\circ} \mathrm{C}$ but not up to $35.0^{\circ} \mathrm{C}$ which represents upper limit value of the thermal comfort of no active persons. This means that analysed clothing systems are still suitable for wearing at $25^{\circ} \mathrm{C}$, although upon subjective evaluations, test persons felt a little uncomfortable, because it was warm. The feeling of thermal comfort is achieved at an ambient temperatures of $20^{\circ} \mathrm{C}$, where mean skin temperature values range between $33.0^{\circ} \mathrm{C}$ and $34.0^{\circ} \mathrm{C}$, and at an ambient temperatures of $15^{\circ} \mathrm{C}$, where range between $31.5^{\circ} \mathrm{C}$ (during walking) and $33.0^{\circ} \mathrm{C}$ (while sitting). In spite of little lower mean skin temperature values evident during walking at an ambient temperatures of $15^{\circ} \mathrm{C}$, test persons felt comfortable, which means that clothing systems are suitable for wearing. At an ambient temperature of $10^{\circ} \mathrm{C}$, when test persons wear clothing systems without a coat, mean skin temperatures in average range under the comfort limits $\left(32.0^{\circ} \mathrm{C}\right)$, and from subjective evaluations, it is evident that test persons felt uncomfortable, because they were cold. This means that clothing systems without a coat are not suitable for wearing at and under an ambient temperature of $10^{\circ} \mathrm{C}$.

The results of analysing the influence of phase change materials (PCMs) incorporated in business clothing systems show that PCMs provide a small temporary thermal effect that is reflected in a slight rising or lowering of mean skin temperature during activity changes. The effect of phase change materials in business clothing systems on the thermophysiological comfort of the wearer is shown as a change of mean skin temperature when subjects walk on a treadmill and after walking when they move to a sitting position, as well as in subjective thermal responses of human subjects. It was determined that the perceived differences in value of skin temperature range around $0.5^{\circ} \mathrm{C}$. Furthermore, it was concluded that clothing systems in combination with PCMs do not affect the thermal-physiological comfort of the wearer in warm environment significantly, except at an ambient temperature of $15^{\circ} \mathrm{C}$, where clothing systems in combination with PCMs produce a small heating effect, which is reflected in the increase of mean skin temperature.

The results obtained in this research also provide an applicative character, since the results of the research give important information for clothing manufacturers, for engineering of clothing systems from the point of view of assuring thermal-physiological comfort as one of the more important factors of quality at choosing a collection of clothes.

\section{Acknowledgments}

This research was performed in the Garment Engineering, Physiology and Construction Laboratory of the Institute of 
Engineering Materials and Design at the Faculty of Mechanical Engineering of University of Maribor. The authors would like to thank Professor D. Sc. Jelka Geršak for offering their facilities in order to perform this research.

\section{References}

[1] X. Zhang, "Heat-storage and thermo-regulated textiles and clothing," in Smart Fibres, Fabrics and Clothing, X. Tao, Ed., pp. 34-57, Woodhead, Cambridge, UK, 2001.

[2] E. A. McCullough and H. Shim, "The use of phase change materials in outdoor clothing," in Intelligent Textiles and Clothing, $\mathrm{H}$. R. Mattila, Ed., pp. 63-81, Woodhead, Cambridge, UK, 2006.

[3] M. Mäkinen, "Introduction to phase change materials," in Intelligent Textiles and Clothing, H. R. Mattila, Ed., pp. 21-33, Woodhead, Cambridge, UK, 2006.

[4] W. Bendkowska, J. Tysiak, L. Grabowski, and A. Blejzyk, "Determining temperature regulating factor for apparel fabrics containing phase change material," International Journal of Clothing Science and Technology, vol. 17, no. 3-4, pp. 209-214, 2005.

[5] W. Bendkowska, "Intelligent textiles with PCMs," in Intelligent Textiles and Clothing, H. R. Mattila, Ed., pp. 34-62, Woodhead, Cambridge, UK, 2006.

[6] K. Ghali, N. Ghaddar, J. Harathani, and B. Jones, "Experimental and numerical investigation of the effect of phase change materials on clothing during periodic ventilation," Textile Research Journal, vol. 74, no. 3, pp. 205-214, 2004.

[7] B. A. Ying, Y. L. Kwok, Y. Li, Q. Y. Zhu, and C. Y. Yeung, "Assessing the performance of textiles incorporating phase change materials," Polymer Testing, vol. 23, no. 5, pp. 541-549, 2004.

[8] L. Hes and B. I. Lu, "A new tester for evaluation of thermal efficiency of PCM fabrics in real conditions of use," in Proceedings of the 37th International Symposium on novelties in Textiles, Naravoslovnotehniška fakulteta, Oddelek za tekstilstvo, Ljubljana, Slovenia, June 2007.

[9] J. Kim and G. Cho, “Thermal storage/release, durability, and temperature sensing properties of thermostatic fabrics treated with octadecane-containing microcapsules," Textile Research Journal, vol. 72, no. 12, pp. 1093-1098, 2002.

[10] K. Choi, G. Cho, P. Kim, and C. Cho, “Thermal storage/release and mechanical properties of phase change materials on polyester fabrics," Textile Research Journal, vol. 74, no. 4, pp. 292-296, 2004.

[11] H. Shim, E. A. McCullough, and B. W. Jones, "Using phase change materials in clothing," Textile Research Journal, vol. 71, no. 6, pp. 495-502, 2001.

[12] H. Chung and G. Cho, "Thermal properties and physiological responses of vapor-permeable water-repellent fabrics treated with microcapsule-containing PCMs," Textile Research Journal, vol. 74, no. 7, pp. 571-575, 2004.

[13] S. X. Wang, Y. Li, H. Tokura et al., "Effect of phase change materials on temperature and moisture distributions in clothing during exercise in cold environment," Journal of Fiber Bioengineering and Informatics, vol. 1, no. 1, pp. 29-40, 2008.

[14] D. Celcar, "Inteligentne tekstilije s fazno spremenljivimi materiali in njihov vpliv na toplotno udobje oblačil [Influence of intelligent textiles with phase-change materials on thermal comfort of clothing]," Tekstilec, vol. 55, no. 1, pp. 45-57, 2012.
[15] K. H. Umbach, "Physiological tests and evaluation models for the optimization of the performance of protective clothing," in Environmental Ergonomics, I. B. Mekjavic, E. W. Banister, and J. B. Morrison, Eds., pp. 139-161, Taylor and Francis, London, UK, 1988.

[16] H. Meinander, "Introduction of a new test method for measuring heat and moisture transmission trough clothing materials and its application on winter work wear," Tech. Rep. 24, VTT Publication, Espoo, Finland, 1985.

[17] International Organization for Standardization, "Textilesphysiological effects-measurement of thermal and watervapour resistance under steady-state conditions (sweating guarded-hotplate test)," ISO 11092, International Organization for Standardization, Geneva, Switzerland, 1993.

[18] International Organization for Standardization, "Textilesdetermination of thermal resistance, part 1: low thermal resistance," ISO 5085-1, International Organization for Standardization, Geneva, Switzerland, 1989.

[19] M. Yoneda and S. Kawabata, "Analysis of transient heat conduction and its applications, part II," Journal of the Textile Machinery Society of Japan, vol. 31, pp. 73-81, 1983.

[20] I. Holmér, "Thermal manikin history and applications," European Journal of Applied Physiology, vol. 92, no. 6, pp. 614-618, 2004.

[21] D. Celcar, H. Meinander, and J. Geršak, "Heat and moisture transmission properties of clothing systems evaluated by using a sweating thermal manikin under different environmental conditions," International Journal of Clothing Science and Technology, vol. 20, no. 4, pp. 240-252, 2008.

[22] K. C. Parsons, Human Thermal Environments. The Effects of Hot, Moderate, and Cold Environments on Human Health, Comfort and Performance, Taylor \& Francis, London, UK, 2nd edition, 2003.

[23] V. T. Bartels, "Physiological comfort of sportswear," in Textiles in Sport, R. Shishoo, Ed., pp. 177-203, Woodhead Publishing in Association with the Textile Institute, Cambridge, UK, 2005.

[24] International Organization for Standardization, "Ergonomicsevaluation of thermal strain by physiological measurements," ISO 9886, International Organization for Standardization, Geneva, Switzerland, 2004.

[25] International Organization for Standardization, "Ergonomics of the thermal environment-assessment of the influence of the thermal environment using subjective judgement scales," ISO 10551, International Organization for Standardization, Geneva, Switzerland, 2004

[26] D. Celcar, J. Geršak, and H. Meinander, "Vrednotenje toplotnih lastnosti tekstilij in njihovih kombinacij = evaluation of textile thermal properties and their combinations," Tekstilec, vol. 53, no. 1-3, pp. 9-32, 2010.

[27] D. Celcar, "Raziskava subjektivnih ocen toplotnega udobja oblačil v toplem okolju = the research of subjective evaluation of clothing's thermal comfort evaluated in hot environment," in 42. simpozij o novostih $v$ tekstilstvu, "Nove tehnologije-da ali ne?", 6. simpozij o novostih v grafiki, "Nove ideje!", B. Simončič, Ed., Ljubljana, Slovenia, June 2011.

[28] D. Celcar, The influence of phase change materials in business garments on thermo physiological comfort [Doctoral thesis], 2008. 

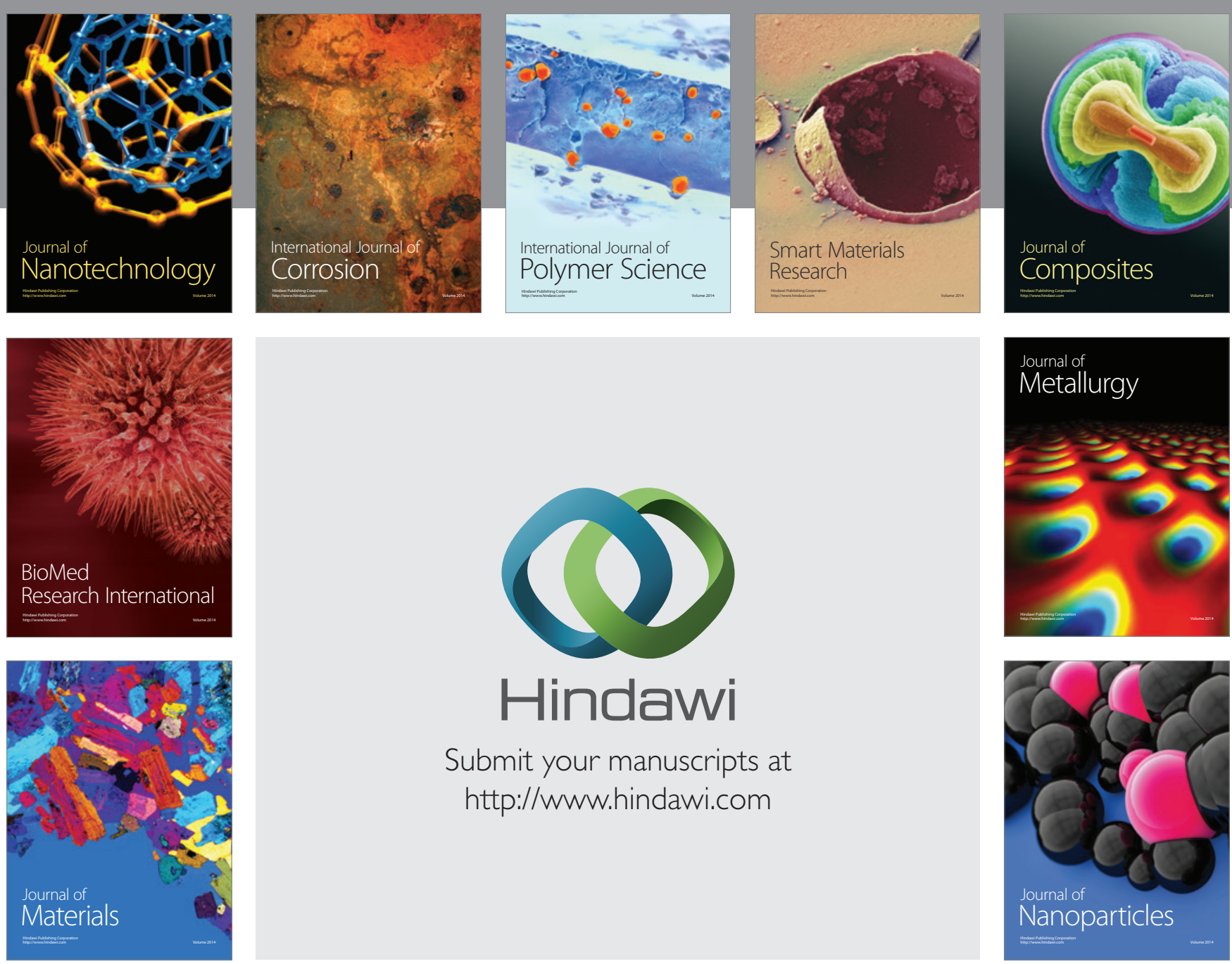

Submit your manuscripts at http://www.hindawi.com
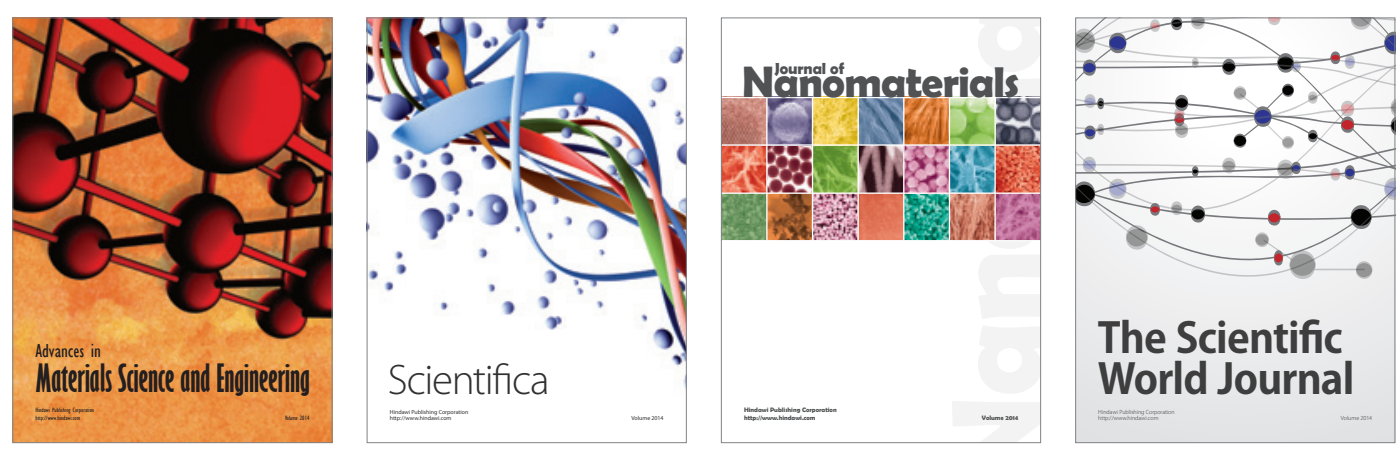

\section{The Scientific World Journal}
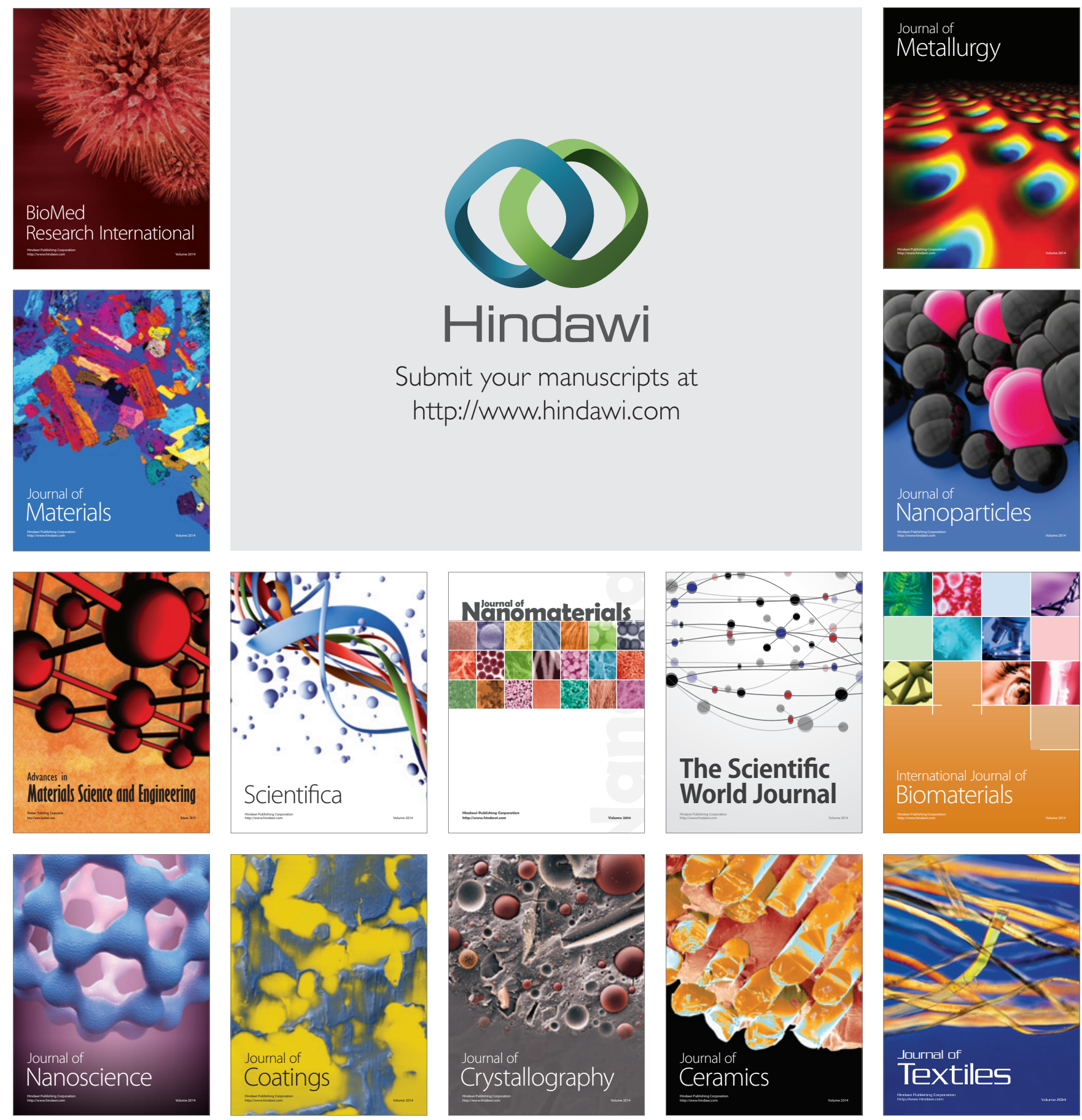